Abstract

\title{
Quasi-Static Measurement with Piezoelectric Sensors in Regard to Structural Health Monitoring of Wind Turbines $^{+}$
}

\author{
Ye Ji Park * and Jannes Kloepfer * \\ Fraunhofer-Institute for Structural Durability and System Reality LBF, 64289 Darmstadt, Germany \\ * Correspondence: Ye.Ji.Park@lbf.fraunhofer.de (Y.J.P.); Jannes.Kloepfer@lbf.fraunhofer.de (J.K.) \\ + Presented at the 5th International Symposium on Sensor Science (I3S 2017), Barcelona, Spain, \\ 27-29 September 2017.
}

Published: 19 December 2017

Structural health monitoring of wind turbines is becoming more important with regard to the increasing demand of wind energy and growing capacities of wind turbines. To predict the lifetime, the mechanical load is measured by strain gauges which are part of an active control system. At present, other sensor principles are investigated for structural health monitoring of wind turbines. In particular, the piezoelectric methodology is interesting due to its specifications but it only operates in dynamic frequency range. Since the blade root strain occurs in a frequency range below $10 \mathrm{~Hz}$, the performance of piezoelectric sensors in quasi-static frequency range is investigated in this work. To simulate an unidirectional strain of a rotor blade, a four-point bending test is performed on various specimens. Sensors of different piezoelectric effects and size are attached on the specimen to measure strain under variable climatic conditions. The effects of climate, frequency, size, strain and host structure on performance of the sensors are assessed. The evaluation approves that the piezoelectric sensor M8507-P2 is suitable for quasi-static strain measurement. The signal conditioning of the piezoelectric sensors is carried out by a charge amplifier module which has been developed in terms of wireless signal conditioning in this work.

Conflicts of Interest: The authors declare no conflict of interest.

(C) 2017 by the authors. Licensee MDPI, Basel, Switzerland. This article is an open access article distributed under the terms and conditions of the Creative Commons Attribution (CC BY) license (http://creativecommons.org/licenses/by/4.0/). 